\title{
FAKTOR-FAKTOR YANG BERHUBUNGAN DENGAN PEMBERIAN ASI EKSKLUSIF DI WILAYAH KERJA PUSKESMAS POASIA KOTA KENDARI PROVINSI SULAWESI TENGGARA
}

\author{
Feryani, S.Si.T ${ }^{1}$, MPH, Nursaidah ${ }^{2}$ \\ ${ }^{1}$ Dosen Jurusan Kebidanan Poltekkes Kemenkes Kendari \\ ${ }^{2}$ Mahasiswa Jurusan Kebidanan Poltekkes Kemenkes Kendari
}

\begin{abstract}
Background: Breast milk (ASI) is the best source of nutrition for babies because it contains various nutrients needed in the growth and development of babies. Giving breast milk is highly recommended until the baby is 6 months old (Utami, 2005). Data on Exclusive Breastfeeding at Poasia Health Center in 2015 amounted to $77.07 \%$ and based on the results of surveys in several Posyandu in the Poasia Community Health Center working area, most of the visiting babies were given formula milk and complementary food for breast milk. This shows that the practice of exclusive breastfeeding is still low which can affect the growth and development of infants so that it will affect the quality of human resources.

Research Objectives: To find out the factors related to exclusive breastfeeding at Posyandu in the working area of Poasia Health Center, Kendari City, Southeast Sulawesi Province in 2016.

Research methods: The research conducted was analytical research with aapproach cross sectional. The study sample was mothers who had babies aged 7 to 24 months in the working area of Poasia Health Center with a total of 77 people. The sampling technique is accidental sampling.

The results of the study: the results of this study were the education of mothers who gave exclusive breastfeeding $80.8 \%$ of secondary education (SMA) mothers and those who did not provide exclusive breastfeeding $100 \%$ of mothers with higher education. Employment of mothers who provide exclusive breastfeeding $54.8 \%$ of working mothers and those who do not provide exclusive breastfeeding $100 \%$ of working mothers. The parity of mothers who gave exclusive breastfeeding was $67.7 \%$ in mothers with no risk (parity 2-3) and those who did not give exclusive breastfeeding $58.7 \%$ in mothers at risk parity (parity 1 and $\geq 4$ ), and there was a relationship between education, employment and maternal parity with exclusive breastfeeding in the working area of Kendari City Poasia Health Center with a value of $\rho_{\text {value }<0.05}$.

Conclusion: The conclusion of this study is that there is a relationship between education, employment and parity with exclusive breastfeeding in the Poasia Community Health Center Working Area.
\end{abstract}

\section{Keywords: Exclusive ASI}

\section{PENDAHULUAN}

Air Susu Ibu (ASI) merupakan sumber nutrisi terbaik bagi bayi karena mengandung berbagai zat gizi yang dibutuhkan dalam pertumbuhan dan perkembangan bayi. Komposisi ASI disesuaikan kematangan saluran pencernaan bayi sehingga meminimalkan risiko gangguan pencernaan, penyakit infeksi dan penyakit non infeksi (Utami, 2005).

Bayi yang diberi susu selain ASI mempunyai risiko 17 kali lebih besar mengalami diare, $50 \%$ terkena infeksi saluran pernafasan (ISPA), kejadian obesitas $40 \%$ (Utami, 2005). Praktek pemberian ASI sampai bayi berusia 6 bulan masih sangat sulit untuk diterapkan. Bayi usia kurang dari 6 bulan telah diberikan berbagai macam makanan pendamping ASI seperti susu formula, bubur susu, pisang, biskuit dan sebagainya. Kegagalan pemberian ASI Eksklusif disebabkan ibu yang harus bekerja di luar rumah untuk memenuhi kebutuhan ekonomi keluarga dan masih kurangnya dukungan 
lingkungan dalam pemberian ASI Eksklusif (AIMI, 2015).

Data tentang pemberian ASI Eksklusif di Puskesmas Poasia tahun 2015 sebesar $77,07 \%$ dan berdasarkan hasil survey di beberapa Posyandu di wilayah kerja Puskesmas Poasia, bayi yang berkunjung sebagian besar telah diberikan susu formula dan makanan pendamping ASI. Hal tersebut menunjukkan masih rendahnya praktek pemberian ASI eksklusif yang dapat berpengaruh terhadap pertumbuhan dan perkembangan bayi sehingga akan mempengaruhi pada kualitas sumber daya manusia. Untuk itu peneliti tertarik untuk meneliti faktor-faktor yang berhubungan dengan pemberian ASI Eksklusif di wilayah kerja Puskesmas Poasia Provinsi Sulawesi Tenggara.

\section{METODE}

\section{Jenis Penelitian}

Penelitian yang dilakukan adalah penelitian analitik dengan pendekatan cross sectional.

\section{Lokasi dan Waktu Penelitian}

Penelitian dilakukan pada bulan Mei 2016 di Posyandu Mawar dan Posyandu Melati Kelurahan Anggoeya Kecamatan Poasia wilayah kerja Puskesmas Poasia Kota Kendari Provinsi Sulawesi Tenggara.

\section{Populasi dan Sampel.}

Populasi penelitian adalah semua ibu menyusui di wilayah kerja Puskesmas Poasia Kota Kendari berjumlah 325 orang.
Sampel penelitian adalah ibu yang mempunyai bayi usia 7 sampai 24 bulan di wilayah kerja Puskesmas Poasia dengan jumlah 77 orang. Tehnik pengambilan sampel dengan cara accidental sampling

\section{Pengumpulan Data}

Data primer diperoleh dengan menggunakan kuesioner berupa identitas responden dan pemberian ASI Eksklusif.

Data sekunder diperoleh dari dokumen Puskesmas Poasia berupa gambaran tempat penelitian.

\section{Pengolahan dan Analisis Data}

Pengolaan data pada hasil penelitian ini yatiu degan cara Editing dilakukan dengan memeriksa kelengkapan data yang terdapat dalam kuesioner penelitian sehingga tidak ada yang kosong/salah, Coding dilakukan dengan mengklasifikasikan data sesuai variabel penelitian, Scoring dilakukan dengan menghitung jumlah kejadian (frekuensi) setiap kategori penelitian dan Tabulating dilakukan dengan memasukkan data hasil penelitian ke dalam tabel frekuensi selanjutnya dianalisis. Data penelitan dianalisis dengan menggunakan uji Chi-Square menggunakan bantuan paket program SPSS.

\section{HASIL}

Berdasarkan hasil pengumpulan data yang dilaksanakan pada bulan Mei 2016 di Posyandu Mawar dan Posyandu MelatiKeluarahan Anggoeya wilayah kerja pada 77 ibu yang mempunyai bayi usia 7 sampai 24 bulan (bawah dua tahun/baduta) diperoleh data sebagai berikut :

Tabel 1. Distribusi Penduduk Wilayah Kerja Puskesmas Poasia Berdasarkan Kelurahan Tahun 2015

\begin{tabular}{clccc}
\hline No & \multicolumn{1}{c}{ Kelurahan } & Pria & Wanita & Total \\
\hline 1 & Anduonohu & 5.045 & 4.955 & 10.000 \\
2 & Rahandouna & 5.579 & 5.273 & 10.852 \\
3 & Anggoeya & 2.532 & 2.413 & 4.945 \\
4 & Mata Bubu & 645 & 616 & 1.261 \\
& Total & $\mathbf{1 3 . 8 0 1}$ & $\mathbf{1 2 . 4 8 1}$ & $\mathbf{2 7 . 0 5 8}$ \\
\hline
\end{tabular}

Berdasarkan Tabel 1 diketahui bahwa jumlah penduduk di Wilayah kerja Puskesmas Poasia pada tahun 2015 berjumlah 27.058 jiwa yang tersebar di 4 wilayah kelurahan. 
Tabel 2. Distribusi Frekuensi Data Responden Berdasarkan Variabel Penelitian di Puskesmas Poasia Tahun 2016

\begin{tabular}{|c|c|c|}
\hline Variabel & Frekuensi & Persentase $(n=77)$ \\
\hline \multicolumn{3}{|l|}{ Pendidikan } \\
\hline Dasar & 47 & 61,03 \\
\hline Menengah & 26 & 33,7 \\
\hline Tinggi & 4 & 5,1 \\
\hline \multicolumn{3}{|l|}{ Pekerjaan } \\
\hline Bekerja & 4 & 5,2 \\
\hline Tidak Bekerja & 73 & 94,8 \\
\hline \multicolumn{3}{|l|}{ Paritas } \\
\hline Berisiko & 46 & 59,7 \\
\hline Tidak Berisiko & 31 & 40,3 \\
\hline \multicolumn{3}{|l|}{ Pemberian ASI Eksklusif } \\
\hline $\mathrm{Ya}$ & 40 & 52 \\
\hline Tidak & 37 & 48 \\
\hline
\end{tabular}

Sumber : Data Primer Terolah

Berdasarkan tabel 2, hasil penelitian yang dilakukan di wilayah kerja Puskesmas Poasia pendidikan responden mayoritas adalah pendidikan dasar (SD dan SMP) sebanyak $61,03 \%$, pendidikan responden berdasarkan pekerjaan sebagian besar ibu yang tidak bekerja (hanya sebagai ibu rumah tangga) sebanyak 94,8\%, sedangkan paritas ibu berisiko (P1 dan 24 ) sebanyak 59,7\% dan ibu yang memberikan ASI Eksklusif sebesar 52\%.

Tabel 3. Hubungan Pendidikan dengan Pemberian ASI Eksklusif di Puskesmas Poasia Tahun 2016

\begin{tabular}{|c|c|c|c|c|c|c|c|}
\hline \multirow[t]{3}{*}{ Pendidikan } & \multicolumn{4}{|c|}{ Pemberian ASI Eksklusif } & \multirow{2}{*}{\multicolumn{2}{|c|}{ Total }} & \multirow[t]{3}{*}{$\mathbf{P}$} \\
\hline & \multicolumn{2}{|c|}{$\mathrm{Ya}$} & \multicolumn{2}{|c|}{ Tidak } & & & \\
\hline & $\mathrm{N}$ & $\%$ & $\mathrm{~N}$ & $\%$ & $\mathrm{~N}$ & $\%$ & \\
\hline Dasar & 19 & 40,4 & 28 & 59,6 & 47 & 100 & 0,00 \\
\hline Menengah & 21 & 80,8 & 5 & 19,2 & 26 & 100 & \\
\hline Tinggi & 0 & 0 & 4 & 100 & 4 & 100 & \\
\hline Total & 40 & 51,9 & 37 & 48,1 & 77 & 100 & \\
\hline
\end{tabular}

Sumber : Data Primer Terolah

Pada tabel 3 menunjukkan pendidikan ibu yang memberikan ASI Eksklusif 80,8\% ibu pendidikan menengah (SMA) dan yang tidak memberikan ASI Eksklusif 100\% ibu dengan pendidikan tinggi. Hasil uji statistik dengan menggunakan chi square menggunakan paket program SPSS diperoleh nilai $\chi^{2}$ hitung lebih besar dari $\chi^{2}$ tabel $(15,476>3,841)$ dan dan nilai $\rho_{\text {value }}<0,05$ sehingga Ho ditolak dan $\mathrm{Ha}$ diterima, bahwa ada hubungan pendidikan ibu dengan keberhasilan pemberian ASI Eksklusif di wilayah kerja Puskesmas Poasia. 
Tabel 4. Hubungan Pekerjaan dengan Pemberian ASI Eksklusif di Puskesmas Poasia Tahun 2016

\begin{tabular}{|c|c|c|c|c|c|c|c|}
\hline \multirow[t]{3}{*}{ Pekerjaan } & \multicolumn{4}{|c|}{ Pemberian ASI Eksklusif } & \multirow{2}{*}{\multicolumn{2}{|c|}{ Total }} & \multirow[t]{3}{*}{$\mathbf{P}$} \\
\hline & \multicolumn{2}{|c|}{ Ya } & \multicolumn{2}{|c|}{ Tidak } & & & \\
\hline & $\mathrm{N}$ & $\%$ & $\mathrm{~N}$ & $\%$ & $\mathrm{~N}$ & $\%$ & \\
\hline Bekerja & 0 & 0 & 4 & 100 & 4 & 100 & 0,03 \\
\hline Tidak Bekerja & 40 & 54,8 & 33 & 45,2 & 73 & 100 & \\
\hline Total & 40 & 51,9 & 37 & 48,1 & 77 & 100 & \\
\hline
\end{tabular}

Sumber : Data Primer Terolah

Pada tabel 4 menunjukkan, ibu yang memberikan ASI Eksklusif 54,8\% pada ibu yang tidak bekerja dan yang tidak memberikan ASI Eksklusif 100\% adalah ibu yang bekerja. Hasil uji statistik dengan menggunakan chi square menggunakan paket program SPSS diperoleh nilai $\chi^{2}$ hitung lebih besar dari $\chi^{2}$ tabel $(4,561>3,841)$ nilai $\rho_{\text {value }}<0,05$ sehingga Ho ditolak dan Ha diterima, bahwa ada hubungan pekerjaan ibu dengan keberhasilan pemberian ASI Eksklusif di wilayah kerja Puskesmas Poasia.

Tabel 5. Hubungan Paritas dengan Pemberian ASI Eksklusif di Puskesmas Poasia Tahun 2016

\begin{tabular}{|c|c|c|c|c|c|c|c|}
\hline \multirow[t]{3}{*}{ Paritas } & \multicolumn{4}{|c|}{ Pemberian ASI Eksklusif } & \multicolumn{2}{|c|}{ Total } & \multirow[t]{3}{*}{$\mathbf{P}$} \\
\hline & \multicolumn{2}{|c|}{$\mathrm{Ya}$} & \multicolumn{2}{|c|}{ Tidak } & & & \\
\hline & $\mathrm{n}$ & $\%$ & $\mathrm{~N}$ & $\%$ & $\mathrm{~N}$ & $\%$ & \\
\hline Berisiko & 19 & 41,3 & 27 & 58,7 & 46 & 100 & 0,02 \\
\hline Tidak Berisiko & 21 & 67,7 & 10 & 32,3 & 31 & 100 & \\
\hline Total & 40 & 51,9 & 37 & 48,1 & 77 & 100 & \\
\hline
\end{tabular}

Sumber : Data Primer Terolah

Pada tabel 5 menunjukkan paritas ibu yang memberikan ASI Eksklusif $67,7 \%$ pada ibu paritas tidak berisiko (paritas 2-3) dan yang tidak memberikan ASI Eksklusif 58,7\% pada ibu paritas berisiko (paritas 1 dan $\geq 4$ ). Hasil uji statistik dengan menggunakan chi square

\section{PEMBAHASAN}

1. Pendidikan

Hasil penelitian menunjukkan ada hubungan antara pendidikan dengan pemberian ASI Eksklusif di Wilayah Kerja Puskesmas Poasia. Hasil penelitian sejalan dengan penelitian yang dilakukan oleh Maria (2013) bahwa ada hubungan bermakna antara pekerjaan dengan pemberian ASI eksklusif di posyandu Tanah Boleng Adonara Kabupaten Flores Timur.

Orang yang berpendidikan tinggi cenderung mempunyai keinginan tinggi untuk mengakses informasi lebih luas menggunakan paket program SPSS diperoleh nilai $\chi^{2}$ hitung lebih besar dari $\chi^{2}$ tabel $(5,186>3,841)$ nilai $\rho_{\text {value }}<0,05$ sehingga Ho ditolak dan Ha diterima, bahwa ada hubungan paritas ibu pemberian ASI Eksklusif di wilayah kerja Puskesmas Poasia.

karena rasa ingin tahu mencari informasi dan memahami informasi yang baru termasuk tentang ASI eksklusif. Semakin tinggi pendidikan yang ditempuh seseorang maka akan semakin baik pengetahuan yang dimiliki dibandingkan pada ibu dengan tingkat pendidikan yang rendah.

Pengetahuan dan sikap seseorang terhadap kesehatan merupakan salah satu faktor predisposisi yang mempengaruhi perilaku seseorang, jadi jika seorang ibu hamil tidak pernah mendapatkan informasi atau penyuluhan mengenai pemberian ASI eksklusif dapat berpengaruh dalam 
memberikan ASI eksklusif pada bayinya dikemudian hari (Notoadmodjo, 2003).

Hasil penelitan Arifin Siregar (2004) dalam Windayanti (2010) alasan ibu tidak menyusui bayi pada kehidupan perkotaan karena kurangnya pengertian dan pengetahuan ibu tentang manfaat ASI dan meyusui yang menyebabkan ibu terpengaruh kepada susu formula. Kesehatan/status gizi bayi serta kelangsungan lebih baik pada ibu yang berpendidikan tinggi. Hal ini karena ibu yang berpendidikan tinggi memiliki pengetahuan yang luas serta kemampuan untuk menerima informasi lebih tinggi.

2. Pekerjaan

Hasil penelitian menunjukkan ada hubungan antara pekerjaan dengan pemberian ASI Eksklusif di Wilayah Kerja Puskesmas Poasia. Hasil penelitian sejalan dengan penelitian yang dilakukan oleh Maria (2013) bahwa ada hubungan bermakna antara pekerjaan dengan pemberian ASI eksklusif di posyandu Tanah Boleng Adonara Kabupaten Flores Timur.

Pekerjaan ibu dapat mempengaruhi pengetahuan dan kesempatan ibu dalam memberikan ASI eksklusif. Bekerja bukan alasan untuk menghentikan pemberian ASI eksklusif. Pengetahuan yang benar tentang menyusui, adanya perlengkapan memerah ASI, dan dukungan lingkungan kerja, seorang ibu yang bekerja dapat tetap memberikan ASI secara eksklusif (Utami, 2005).

Teori Green mengatakan perilaku pemberian ASI eksklusif dapat dipengaruhi oleh pengetahuan, pendidikan, sikap dan pekerjaan, adanya faktor pendukung dan faktor penguat. Pekerjaan adalah suatu pilihan atau suatu kebutuhan dimana pekerjaan menuntut ibu untuk meninggalkan bayi pada usia dini dalam waktu yang cukup lama setiap hari sehingga keberhasilan ASI Eksklusif rendah (Notoatmodjo, 2003).

3. Paritas

Hasil penelitian menunjukkan ada hubungan antara paritas dengan pemberian ASI Eksklusif di Wilayah Kerja Puskesmas Poasia. Paritas ibu mempengaruhi dalam perawatan bayi baru lahir (Suparyanto, 2010). Ibu dengan paritas 1 biasanya belum mempunyai pengalaman yang cukup dalam perawatan bayi termasuk pemberian ASI eksklusif. Selain itu ibu dengan paritas yang tinggi ( $>4$ ) mempunyai pengalaman yang banyak dalam perawatan bayi baru lahir, namun dengan banyaknya tugas dan tanggung jawab dalam mengurus rumah tangga mempengaruhi emosional ibu. Kondisi emosional merupakan faktor yang menunjang keberhasilan pemberian ASI Eksklusif karena emosi ibu yang terganggu dapat menghambat proses pembentukan dan pengeluaran ASI (Utami, 2005).

Hasil penelitian sejalan dengan penelitian yang dilakukan oleh Maria (2013) bahwa ada hubungan paritas dengan pemberian ASI eksklusif di posyandu Tanah Boleng Adonara Kabupaten Flores Timur. Semakin tinggi tingkat paritas ibu maka pengaruh positif terhadap pemberian ASI eksklusif.

\section{KESIMPULAN DAN SARAN}

Kesimpulan dari penelitian ini yaitu pendidikan ibu yang memberikan ASI Eksklusif $80,8 \%$ ibu pendidikan menengah (SMA) dan yang tidak memberikan ASI Eksklusif $100 \%$ ibu dengan pendidikan tinggi. Pekerjaan ibu yang memberikan ASI Eksklusif $54,8 \%$ ibu bekerja dan yang tidak memberikan ASI Eksklusif 100\% ibu bekerja. Paritas ibu yang memberikan ASI Eksklusif 67,7\% pada ibu paritas tidak berisiko (paritas 2-3) dan yang tidak memberikan ASI Eksklusif 58,7\% pada ibu paritas berisiko (paritas 1 dan $\geq 4$ ), serta ada hubungan antara pendidikan, pekerjaan dan paritas ibu dengan pemberian ASI Eksklusif di Wilayah kerja Puskesmas Poasia Kota Kendari dengan nilai $\rho_{\text {value }}<0,05$.

Diharapkan penelitian ini dapat memberikan edukasi dan informasi pada ibu tentang persiapan pemberian dan pengelolaan yang baik dan benar khususnya bagi ibu yang bekerja.

\section{DAFTAR PUSTAKA}
AIMI. 2015. Pekan ASI Sedunia (PAS) Tahun 2015 - Menyusui dan Bekerja: Mari Kita Sukseskan. http://aimi- asi.org/pekan-asi-sedunia- pas- tahun-2015 diakses 1 Desember 2015

Coad, J dan Dunstall. 2007. Mengenal ASI eksklusif. Jakarta: EGC 
Fraser,DM dan Cooper M.A. 2009. Myles Buku Ajar Bidan. Jakarta: EGC

Kementerian Kesehatan. R.I 2014. Dirjen Bina Gizi \& Kesehatan Ibu Dan Anak. http://www.kemenkes.go.id/a/dirjenbina-gizi-kesehatan-ibu- dan-anak diakses Maret 2016.

Kementerian Kesehatan. R.I. 2010. Riset Kesehatan Dasar.

Kementerian Kesehatan. R.I . 2010. Pedoman Pekan ASI Sedunia (PAS). Jakarta : Kemenkes R.I

Maria, A.S. 2014. Faktor-faktor yang berhubungan dengan pemberian asi Eksklusif di posyandu Tanah Boleng Adonara Kabupaten Flores

Timur. Program Studi Keperawatan A. STIK SINT Carolus. Jakarta.

Muchtar, R., 2008. Pentingnya ASI. http://surabaya.webs.com diakses tanggal 23 November 2015.

Notoatmodjo, S. 2007. Metodologi Penelitian Kesehatan. Jakarta : Rineka Cipta.

Notoatmodjo, S. 2003. Pendidikan dan Perilaku Kesehatan. Jakarta : Rineka Cipta. Jakarta

Perinasia. 2004. Bahan Bacaan Manajemen Laktasi Edisi 2. Jakarta.
Prasetyono, D.S. 2009. ASI eksklusif : Pengenalan dan Praktik. Yogyakarta : Diva Press

Utami. R. 2005. Mengenal ASI Eksklusif. Jakarta : Trubus Agriwidya.

Suparyanto, 2010. Konsep Paritas. BKKBN: Jakarta

Supriadi. 2002. Kiat Sukses Menyusui. Buku pegangan seputar manfaat menyusui dan permasalahannya, Jakarta.

Suririnah. 2009. Buku Pintar Merawat Bayi 012 Bulan. Jakarta: Gramedia Pustaka Utama.

Undang-Undang R.I. No. 20 Tahun 2003 Tentang Sistem Pendidikan Nasional.

Wiknjosastro, H. 2012. Ilmu Kebidanan. Jakarta : Yayasan Bina Pustaka Sarwono Prawirohardjo.

Windayanti. 2010. Hubungan Umur dan Tingkat Pendidikan Ibu Terhadap Pemberian ASI Eksklusif di Kabupaten Bengkulu Utara. KTI. Fakultas Ilmu Kesehatan. Universitas Ratu Samban Bengkulu Utara.

WHO, 2004. Breasfeeding Counselling. UNICEF, Nutrition Section, USA, diterjemahkan oleh Janur ADV, $H M H B$ Project: Sultra. 